\title{
LONG-TERM EFFECTS OF 4-YEAR LONGITUDINAL SCHOOL-BASED PHYSICAL ACTIVITY INTERVENTION ON THE PHYSICAL FITNESS OF CHILDREN AND YOUTH DURING 7-YEAR FOLLOW- UP ASSESSMENT
}

\author{
Gregor Jurak', Ashley Cooper ${ }^{2}$, Bojan Leskošek', Marjeta Kovač ${ }^{1}$ \\ ${ }^{1}$ Faculty of Sport, University of Ljubljana, Ljubljana, Slovenia \\ ${ }^{2}$ Centre for Exercise, Nutrition and Health Sciences, University of Bristol, Bristol, United Kingdom
}

\section{SUMMARY}

Many school-based physical activity (PA) interventions have been developed, but only a few have assessed their long-term effects. A PA intervention taking place in the first four years of some Slovenian primary schools entails an enhanced physical education (PE) curriculum, including two extra lessons of PE per week, a wider selection of PE content, and additional outdoor education delivered by both a specialist PE teacher and a general teacher. The effects of the intervention on children's physical fitness (motor tasks and anthropometry) were evaluated within a quasiexperimental study. In total, 324 children from nine Slovenian primary schools either received the enhanced curriculum (intervention $(n=160))$ or standard PE (control $(n=164))$, and were followed for a four-year intervention period and seven years post intervention. Data from the SLOFIT database were used to compare differences in the physical fitness of children each year. Linear Mixed Models were used to test the influence of the PA intervention.

Over an 11-year period, the PA intervention group significantly differed in all motor tasks, but not in anthropometric measures or body mass index, after controlling for year of measurement and sex. Differences between the control and intervention groups decreased with time.

This study highlights the importance of tracking the long term effects of PA interventions. PA intervention in the first four years of Slovenian primary school offers the possibility of improving physical performance in children; initiatives aiming to increase their performance (physical fitness, physical activity) and health outcomes are warranted.

Key words: school prevention programmes, physical education, physical development, childhood obesity, motor performance, long-term effects

Address for correspondence: G. Jurak, Faculty of Sport, Gortanova 22, SI-1000 Ljubljana, Slovenia. E-mail: gregor.jurak@fsp.uni-lj.si

\section{INTRODUCTION}

Poor physical fitness in childhood and adolescence is associated with many preventable diseases in adulthood, and represents a serious current and future public health problem (1). Regular physical activity (PA) can lead to improvements in numerous physiological and morphological variables in children and adolescents (2) and forms the basis for many interventions (3-11). Schools have been a popular setting for such interventions, as they offer continuous, intensive contact with children, and the school infrastructure and physical environment, policies, curricula, and staff have the potential to positively influence children's health. There are many school-based PA intervention programmes throughout the world, differing in setting, duration and content. Reviews of these intervention programmes $(3,5,6,10,11)$ show that school-based PA intervention programmes may help children and adolescents attain a higher PA level and a healthy weight, but the results are inconsistent and short-term.

Many school-based PA interventions have been based upon physical education (PE) classes $(5,6)$, since PE serves both to prepare students to be physically educated persons, teach- ing them the importance of regular PA for health and building skills that support active lifestyles (12-15), and promotes motor development and physical fitness which are closely related to children's cognitive and emotional-social development (16-18). One such PA intervention programme has been delivered in Slovenia since 1984 , and is currently offered by $7 \%$ of primary schools (19). The intervention comprises extra volume and quality of PE, offering extra time spent in PE, enhanced delivery and a greater range of opportunities for outdoor physical activities and sports. The programme is carried out with the permission of the school council, and the organisation and contents supplement the curriculum.

One of the important outcomes of such school-based PA interventions is the programme's potential influence on the physical fitness of children. Previous studies (20-23) have shown the positive effects of such a PA intervention in Slovenian schools on the physical fitness of children, yet all these studies were limited to assessing physical fitness at the end of intervention and did not explore longer term maintenance of fitness changes. The present study sought to determine to what extent the effects of this four-year PA intervention programme on the physical fitness 
of children were maintained during the intervention period and for up to seven years after the intervention.

\section{MATERIALS AND METHODS}

\section{Participants}

The sample consisted of 324 children from 27 classes from nine Slovenian primary schools. Schools were from urban locations in different regions of Slovenia, and were eligible for inclusion if they offered both standard PE and enhanced PE classes. All schools that met this criterion were included in the study.

The sample comprised 74 girls and 86 boys attending enhanced PE classes (intervention group) and 84 girls and 80 boys receiving standard PE (controls). Baseline age in both groups was similar (intervention group mean 7.76, SD 0.33; control group mean 7.71, SD 0.32)

\section{Instruments}

Data were collected within SLOFIT, the Slovenian system for monitoring children's physical fitness, which was first implemented in 1987 (24). The SLOFIT test battery includes eight motor tests (arm plate tapping, standing long jump, polygon backwards, sit-ups, standing reach touch, bent arm hang, 60-meter run, and 600-meter run), and three anthropometric measurements (body height, body weight and triceps skinfold thickness). Measurements are taken annually in April during PE classes. All measurements are conducted according to the standard protocol by trained PE teachers who have completed a 30 -hour course in anthropometric measurement and a 15-hour course in the measurement of motor function. To include and evaluate children's measurements in the SLOFIT system, and to use the data for scientific purposes, children are required to provide the written consent of their parents; throughout the existence of this system, the response rates have remained above $94 \%$ in primary schools and between $60 \%$ and $86 \%$ in secondary school. Currently, about 210,000 children and adolescents take part in SLOFIT every year.

\section{PA Intervention}

The enhanced PE programme aims to positively influence the physical and motor development of children, and to build skills that support active lifestyles. The programme is delivered in the first four years of schooling, and includes three standard PE lessons (45 minutes per lesson) delivered by general teachers and two extra lessons of PE per week, delivered with the joint teaching of a specialist PE teacher and a generalist teacher. The lesson content and structure are determined by the specialist teachers. In addition, the enhanced programme includes a wider selection of PE content (e.g. other sports), which can also be conducted outside of school. The intervention lessons usually take place in the middle of the daily schedule. The $\mathrm{PE}$ activities that schools offered in courses were also usually organised during the educational process and less frequently after school hours, on holidays or on weekends (19).

\section{Design}

The study was quasi-experimental, with the school as the unit of intervention. To exclude as many environmental factors as possible (conditions for PE offered by individual schools and the impact of the school social environment), nine primary schools that performed both PA intervention and regular classes (control group) were selected in the study (23).

The SLOFIT database was used to extract the annual data for the eight motor tests and the three anthropometric measurements for every child included in the eleventh year of schooling (after four years of intervention and seven years post-intervention). The baseline and all follow-up measurements took place at primary and secondary schools during PE lessons every April from 2000 to 2010.

\section{Data Analysis}

A linear mixed model was constructed for each dependent variable (all eleven tests from SLOFIT and body mass index) to test the influence of the intervention on the physical fitness of children controlling for sex and year of measurement. Body mass index (BMI) was calculated from body weight and height as weight (in $\mathrm{kg}$ ) divided by squared height (in $\mathrm{m}$ ). A total of 445 students were involved in the study, however, 121 students were excluded from the analysis ( $27.2 \%$ drop-out) due to high proportions of randomly occurred missing values (most of drop-out occurred from nine to eleventh year of schooling, when children attended high schools), while for students with less than three missing values in each year, missing data were imputed using the EM algorithm. Hence, sample consisted of 324 students (Table 1).

The R 2.13 (http://r-project.org) programming environment with nlme library and lme procedure function was used for model construction. Default options for all arguments of the function were chosen (i.e. restricted maximum-likelihood method for model fit, no within-group correlations, and homoscedastic within-group errors). After testing of several models for goodness of fit and parsimony (taking statistical significance of model effect, AIC and BIC criteria into account), programme, year, gender and programme: year and year: sex interactions were used as fixed effects and subject (within class), class (within school) and school as random effects. nlme ANOVA function was used to evaluate fixed effects of the model.

Table 1. Description of the number of participants in the study

\begin{tabular}{|l|c|c|c|}
\hline $\begin{array}{l}\text { Students involved } \\
\text { in the study }\end{array}$ & Control & Intervention & Total \\
\hline Boys & 115 & 113 & 228 \\
\hline Girls & 114 & 103 & 217 \\
\hline Total & 229 & 216 & 445 \\
\hline Drop-out \\
\hline Boys & 35 & 27 & 62 \\
\hline Girls & 30 & 29 & 59 \\
\hline Total & 65 & 56 & 121 \\
\hline Analysed sample of students & 80 & 86 & 166 \\
\hline Boys & 84 & 74 & 158 \\
\hline Girls & 164 & 160 & 324 \\
\hline Total &
\end{tabular}




\section{RESULTS}

Only small differences were observed between the intervention and control group in the morphological variables at baseline. The children from both groups had similar physical development (Fig. 1), becoming taller and heavier. The results for triceps skinfold thickness differed by sex, with girls gaining subcutaneous fat throughout the observation period (7- to 17-yearolds) and the boys losing it after the fourth year. Analysed by intervention arm, at the end of the PA intervention programme (4th year), the intervention group had increased their triceps skinfold thickness in comparison to the control group; however, differences at the end of the observed period (11th year) were similar to the baseline.

The children from both groups had also similar motor development (Fig. 2). Differences were found between the intervention and control group in motor variables at baseline, with children from intervention group generally having better results in all motor tests (lower results in the tests polygon backwards, $60-\mathrm{m}$ and 600-metre run mean better fitness) in the observed period. It can be seen that differences between groups remained the same or became smaller throughout the 11-year period. In particular, the trend of decreasing the differences after the end of intervention (4th year) can be observed in the polygon backwards, sit-ups, bent arm hang, and 600-metre run.

After controlling for year of measurement and sex, the programme groups (intervention/control) significantly differed in all motor tasks, but not in anthropometric measures. However, there was an interaction with time in six of the eight motor tasks as well as in BMI and triceps skinfold programme (Table 1). ANOVA for the fixed mixed-model effects also revealed that the sex and age of students had much stronger impacts on physical fitness than the programme. As expected from results presented in Figures 1 and 2 most of year: sex interactions (except for sit-ups and bent arm hang) were statistically significant.

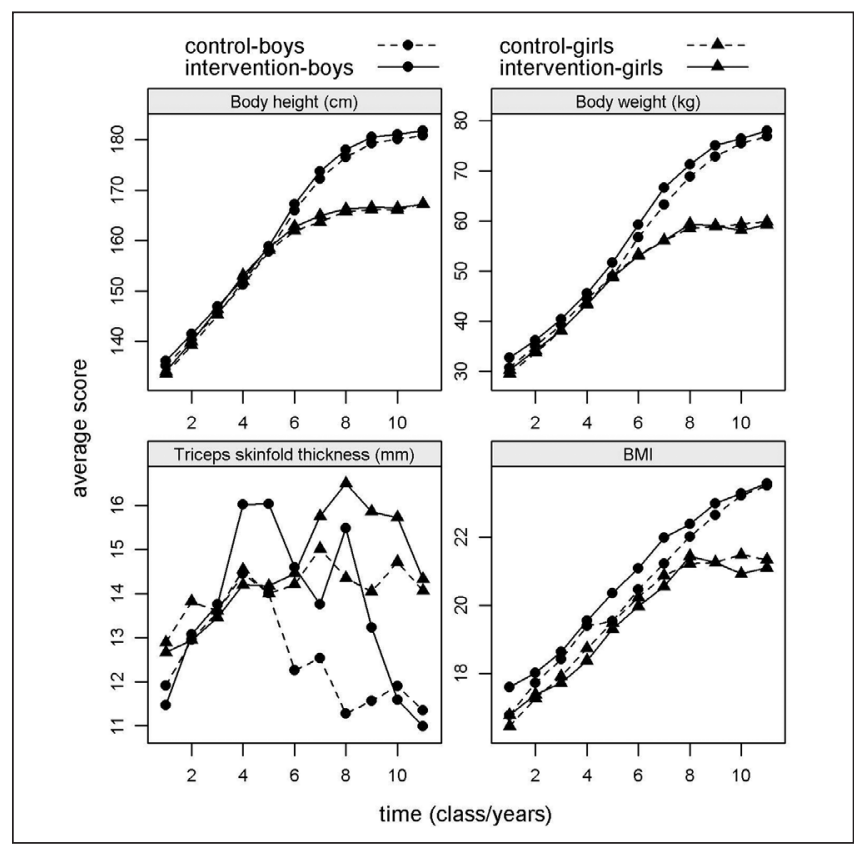

Fig.1. Mean values of morphological variables by time (year of observation), programme and sex.

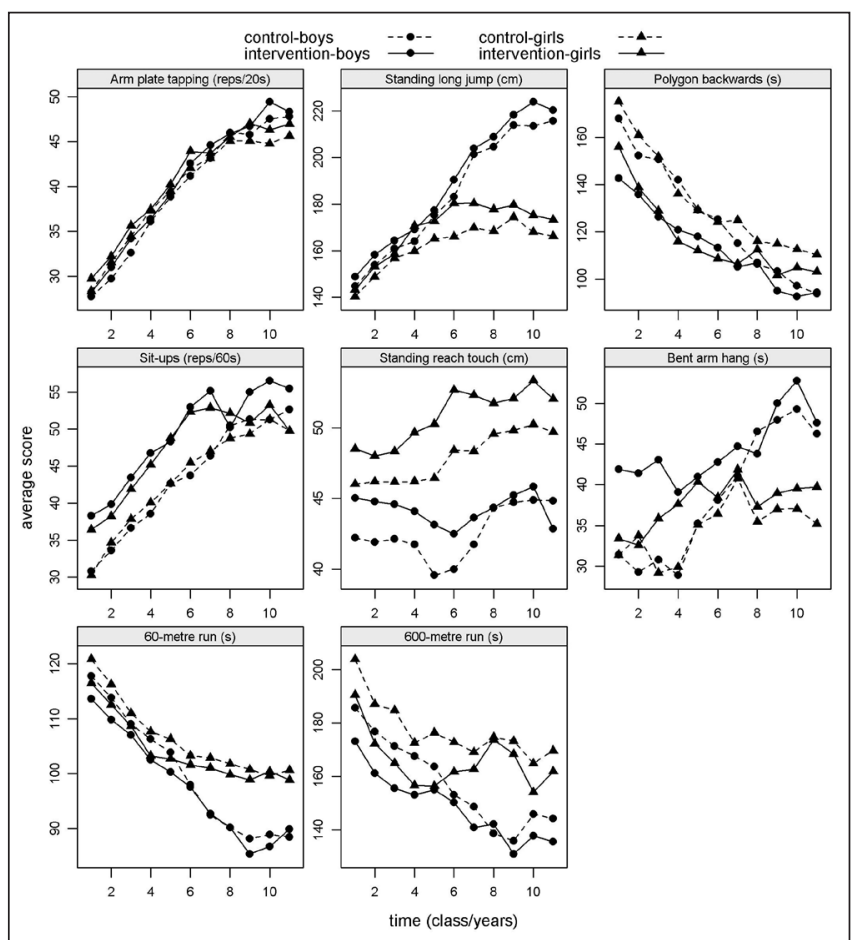

Fig. 2. Mean values of motoric variables by time (year of observation), programme and sex.

\section{DISCUSSION}

This study showed that the enhanced PA intervention programme delivered in the first four years in some Slovenian schools had limited long-term impact on children's physical fitness in comparison to standard PE classes. The post intervention evaluations showed that the intervention group continued to achieve better results than the control group, but differences between the groups decreased with increasing time of follow-up, especially in the polygon backwards, sit-ups and 600-metre run tasks. Therefore, this PA intervention programme is in line with other interventions in which the obtained positive intervention effects could not be sustained (25-27).

The PA intervention in Slovenian schools is a long-term intervention, in contrast to the majority of interventions elsewhere using supervised programmes of moderate to vigorous physical activity of 30 to 45 minutes, three to five days per week, which last less than six months (3). In the four-year period of the intervention, 280 more lessons of PE were delivered (total of 700 lessons) to the intervention group, and positive short and long-term effects would be expected. However, the results do not confirm this expectation, raising questions about the reasons for this.

The physical development of both groups was as expected for the age group ( 7 to 17 years) and time of study (2000-2010). Subcutaneous fat increased in both sexes to the age of 10 and then decreased in boys, with girls continuing to gain fat $(28,29)$. The secular trend of an increasing proportion of overweight and obesity in boys than in girls also should be mentioned, especially among 11- to 13-year-old boys, who already show a prolongation of gain of subcutaneous fat (30).

Long-term interventions have the advantage of maintaining positive health-related behaviours (31), yet despite this PA intervention had no significant effect on BMI or adiposity. Such 
Table 2. Statistical significance for ANOVA for standardised values of variables by programme, year of observation (age of students), sex, programme: year interaction and year: sex interaction

\begin{tabular}{|l|c|c|c|c|c|}
\hline \multirow{2}{*}{} & \multicolumn{5}{|c|}{ ANOVA for the fixed mixed-model effects } \\
\cline { 2 - 6 } & programme & year & sex & programme: year & year: sex \\
\hline Body height & 0.190 & $<0.0001$ & $<0.0001$ & 0.782 & $<0.0001$ \\
\hline Body weight & 0.624 & $<0.0001$ & $<0.0001$ & 0.118 & $<0.0001$ \\
\hline BMI & 0.940 & $<0.0001$ & $<0.0001$ & 0.010 & 0.001 \\
\hline Triceps skinfold thickness & 0.848 & $<0.0001$ & $<0.0001$ & $<0.0001$ & $<0.0001$ \\
\hline Arm plate tapping & 0.001 & $<0.0001$ & 0.733 & 0.206 & $<0.0001$ \\
\hline Standing long jump & 0.001 & $<0.0001$ & $<0.0001$ & 0.003 & $<0.0001$ \\
\hline Polygon backwards & $<0.0001$ & $<0.0001$ & 0.017 & $<0.0001$ & 0.000 \\
\hline Sit-ups & $<0.0001$ & $<0.0001$ & 0.372 & 0.000 & 0.134 \\
\hline Standing reach touch & 0.000 & $<0.0001$ & $<0.0001$ & 0.012 & $<0.0001$ \\
\hline Bent arm hang & 0.008 & $<0.0001$ & 0.015 & 0.348 & 0.229 \\
\hline 60 -metre run & 0.009 & $<0.0001$ & $<0.0001$ & 0.014 & $<0.0001$ \\
\hline 600 -metre run & $<0.0001$ & $<0.0001$ & $<0.0001$ & 0.013 & $<0.0001$ \\
\hline
\end{tabular}

non-effectiveness has also been observed in some other PA interventions (32-36). Studies using objective methods to investigate the relationship between PA and adiposity have shown conflicting results, some studies show overweight status or adiposity to be inversely related to PA $(37,38)$ whilst others report no association (39-42). In addition, the study of Ekelund et al. (43) showed that only obese children, and not overweight children, are involved in less PA than their normal-weight peers.

The initial differences in motor tests indicate that children with better physical fitness more frequently enrolled in the enhanced PE programme, which was confirmed also in previous studies $(22$ 44). One possible explanation may be that children enrolled in the PA intervention have parents with more positive attitudes to an active lifestyle, and who are prepared to pay for such a lifestyle (45), though the monthly contribution ( $€ 11.40$ on average) is not so high that most parents cannot afford for their children to attend the PA intervention (19). Assuming greater family support for children in the PA intervention programme, it might be expected that these children take part in more frequent out-of-school PA than others. The decrease of differences in physical fitness after intervention suggests some other possible explanations. In an overview of findings from PA interventions, De Meester et al. (6) found that improvements in PA levels by school-based interventions are limited to school-related PA with no conclusive transfer to leisure time PA. Specifically, although most school-based programmes intended to achieve a change in lifestyle habits and did not intend to restrict their intervention to changes in school-related PA, intervention in a school setting could have unintentionally focused more on the mechanisms of behaviour change for school-related PA.

One more possible explanation, which should be more thoroughly investigated, is that schools offering the enhanced PE intervention also have a higher level of PE in classes within the regular PE curriculum as a result of the positive transfer of knowledge between generalist teachers (44). In support of this assumption, results of previous study, in which a standardised comparison of physical fitness of interventional and control groups with physical fitness of population was performed, found that children from the control group improved in motor tests in comparison to the population during time of PA intervention. At the end of intervention, the control group also achieved aboveaverage results in motor tests (23).

Therefore, studying the long-term effect of PA intervention remains an even more challenging task. It seems that PA intervention has positive effects, yet its long-term efficiency is questionable. Many factors should be controlled and some other possible outcomes in addition to the physical fitness of children should be investigated to obtain better insight into the impact of PA intervention.

\section{Limitations}

There are limitations to our study, and care should be taken in generalising it to different countries, since there are considerable differences in the organisation and contents of PE curricula and PA interventions around the world. The study was a quasiexperiment and did not control for many important environmental and social factors influencing the physical and motor development of children, although we attempted to control for those factors by sampling classes for the intervention and control groups from the same schools. However, this could also be a weakness due to the possible transfer of knowledge of planning and performing PE among teachers in the intervention and control groups. We were unable to gather the information on teachers' actual PE planning and teaching competencies, which surely influence the quality of curriculum delivery. We also have no information on whether the children's out-of-school activities affected the results.

\section{CONCLUSIONS}

The results of the study reveal the shortfalls of current work in the studied PA intervention. Since less positive results were found in interventions that targeted also other health behaviours in addition to PA $(26,46-48)$, it is recommended that the focus in intervention in Slovenian schools remain on PA, yet the changes should be made to achieve better maintenance effects of the in- 
tervention on physical fitness. On the basis of the findings from other PA interventions $(46,47,49-52)$, better effectiveness could be achieved by:

- introducing more health-oriented contents in PE lessons in programme;

- inclusion of more cooperative, fitness and goal-oriented activities in PE lessons;

- providing sports equipment during recess periods and extracurricular schoolwork;

- parental involvement and support through homework assignments and through supervision.

In addition, the development of the PA intervention should be underpinned by the transfer of knowledge of planning PE, as it has been found that generalist teachers lack skills in this area (53). With the increased competencies of teachers, it will be possible to utilise more moderate-to-intense PA of children as the amount of time that children spend at school is rising. Therefore, children could participate in proper intensity PA as part of their extracurricular schoolwork.

The different school environments (i.e. working hours of parents, socio-cultural status, sports facilities and natural environment, partnership with multiple parties) and the autonomy of teachers require the flexible organisation of PA intervention according to the specifics of the particular school situation and the teacher's competencies, yet it must still serve the same purpose: to build knowledge and skills that support active lifestyles, which should be manifested in better physical and motor development of children. To obtain a more comprehensive picture of the effects of PA intervention, other maintenance effects, such as the socialisation, physical self-concept and academic achievement, should also be studied.

\section{Conflict of Interest}

None declared

\section{REFERENCES}

1. Branca F, Nikogosian H, Lobstein T, editors. The challenge of obesity in the WHO European Region and the strategies for response [Internet]. Copenhagen: WHO Regional Office for Europe; 2007 [cited 2010 Mar 15]. Available from: http://www.euro.who.int/_data/assets/ pdf file/0010/74746/E90711.pdf.

2. Owen CG, Nightingale CM, Rudnicka AR, Sattar N, Cook DG, Ekelund U, et al. Physical activity, obesity and cardiometabolic risk factors in 9to 10-year-old UK children of white European, South Asian and black African-Caribbean origin: the Child Heart And health Study in England (CHASE). Diabetologia. 2010 Aug;53(8):1620-30.

3. Brown T, Summerbell C. Systematic review of school-based interventions that focus on changing dietary intake and physical activity levels to prevent childhood obesity: an update to the obesity guidance produced by the National Institute for Health and Clinical Excellence. Obes Rev. 2009 Jan;10(1):110-41.

4. Kriemler S, Meyer U, Martin E, van Sluijs EM, Andersen LB, Martin BW. Effect of school-based interventions on physical activity and fitness in children and adolescents: a review of reviews and systematic update. Br J Sports Med. 2011 Sep;45(11):923-30.

5. Salmon J, Booth ML, Phongsavan P, Murphy N, Timperio A. Promoting physical activity participation among children and adolescents. Epidemiol Rev. 2007;29:144-59.

6. De Meester F, van Lenthe FJ, Spittaels H, Lien N, De Bourdeaudhuij I. Interventions for promoting physical activity among European teenagers: a systematic review. Int J Behav Nutr Phys Act. 2009 Dec 6;6:82.
7. Camacho-Miñano MJ, LaVoi NM, Barr-Anderson DJ. Interventions to promote physical activity among young and adolescent girls: a systematic review. Health Educ Res. 2011 Dec;26(6):1025-49.

8. Dobbins M, De Corby K, Robeson P, Husson H, Tirilis D. School-based physical activity programs for promoting physical activity and fitness in children and adolescents aged 6-18. Cochrane Database Syst Rev. 2009 Jan 21;(1):CD007651.

9. van Sluijs EM, McMinn AM, Griffin SJ. Effectiveness of interventions to promote physical activity in children and adolescents: systematic review of controlled trials. BMJ. 2007 Oct 6;335(7622):703.

10. Shaya FT, Flores D, Gbarayor CM, Wang J. School-based obesity interventions: a literature review. J Sch Health. 2008 Apr;78(4):189-96.

11. Lavelle HV, Mackay DF, Pell JP. Systematic review and meta-analysis of school-based interventions to reduce body mass index. J Public Health (Oxf). 2012 Aug;34(3):360-9.

12. Sallis JF, Prochaska JJ, Taylor WC. A review of correlates of physical activity of children and adolescents. Med Sci Sports Exerc. 2000 May;32(5):963-75.

13. Ding D, Sallis JF, Kerr J, Lee S, Rosenberg DE. Neighborhood environment and physical activity among youth a review. Am J Prev Med. 2011 Oct;41(4):442-55.

14. Fairclough S, Stratton G. 'Physical education makes you fit and healthy'. Physical education's contribution to young people's physical activity levels. Health Educ Res. 2005 Feb;20(1):14-23.

15. Froberg K, Andersen LB. The importance of physical activity for childhood health. In: Kovač M, Jurak G, Starc G, editors. Proceedings of the 5th International Congress Youth Sport 2010; 2010 Dec 2-4; Ljubljana, Slovenia. Ljubljana: University of Ljubljana; 2010. p. 41-6.

16. Sibley BA, Etnier JL. The relationship between physical activity and cognition in children: A meta-analysis. Pediatr Exerc Sci. 2003;15(3):243-56.

17. Tomporowski PD. Cognitive and behavioral responses to acute exercise in youths: A review. Pediatr Exerc Sci. 2003;15(4):348-59.

18. Kovač M, Strel J. The relations between indicators of intelligence and motor abilities. Kinesiology. 2000;32(1):15-25.

19. Jurak G, Kovač M, Strel J. An analysis of some organisational aspects of sports classes at the end of 8-year-long compulsory primary education. Šport. 2004;52(2):29-34. (In Slovene.)

20. Starc G, Strel J. Influence of the quality implementation of a physical education curriculum on the physical development and physical fitness of children. BMC Public Health. 2012 Jan 20;12:61.

21. Štihec J, Kovač M. The influence of an experimental programme of physical education on the development of some morphologic and motor dimensions of 8 year old pupils. Kinesiologia Slovenica. 1992;1(1):71-4. (In Slovene.)

22. Peternelj B, Škof B, Strel J. Differences between Slovenian pupils attending sport class and those attending a regular school programme. Int J Phys Educ. 2008;45(3):144-51.

23. Jurak G, Kovač M, Strel J. Impact of the additional physical education lessons programme on the physical and motor development of 7- to 10-year-old children. Kinesiology. 2006;38(2):105-15.

24. Strel J, Ambrožič F, Kondrič M, Kovač M, Leskošek B, Štihec J, et al. Sports Educational Chart. Ljubljana: Ministry of Education and Sport; 1997.

25. Tsorbatzoudis H. Evaluation of a school-based intervention programme to promote physical activity: an application of the theory of planned behavior. Percept Mot Skills. 2005 Dec;101(3):787-802.

26. Digelidis N, Papaioannou A, Laparidis K, Christodoulidis T. A one-year intervention in 7 th grade physical education classes aiming to change motivational climate and attitudes towards exercise. Psychol Sport Exerc. 2003;4(3):195-210.

27. 27.Lubans D, Sylva K. Controlled evaluation of a physical activity intervention for senior school students: effects of the lifetime activity program. J Sport Exerc Psychol. 2006;28(3):252-68.

28. Malina RM, Bouchard C, Bar-OR O. Growth, maturation, and physical activity. 2nd ed. Champaign, Ill: Human Kinetics; 2004.

29. Strel J, Kovač M, Jurak G. Physical and motor development, sport activities and lifestyles of Slovenian children and youth - changes in the last few decades. In: Brettschneider WD, Naul R, editors. Obesity in Europe: young people's physical activity and sedentary lifestyles. Frankfurt am Main: Peter Lang; 2007. p. 243-64.

30. Kovač M, Jurak G, Leskošek B. The prevalence of excess weight and obesity in Slovenian children and adolescents from 1991 to 2011. Anthropol Noteb. 2012;18(1):91-103.

31. Manios Y, Kafatos I, Kafatos A; Preventive Medicine and Nutrition Clinic Research Team. Ten-year follow-up of the Cretan Health and Nutrition 
Education Program on children's physical activity levels. Prev Med. 2006 Dec;43(6):442-6.

32. Graf C, Koch B, Falkowski G, Jouck S, Christ H, Staudenmaier K, et al. School-based prevention: effects on obesity and physical performance after 4 years. J Sports Sci. 2008 Aug;26(10):987-94.

33. Sallis JF, McKenzie TL, Alcaraz JE, Kolody B, Faucette N, Hovell MF. The effects of a 2-year physical education program (SPARK) on physical activity and fitness in elementary school students. Sports, Play and Active Recreation for Kids. Am J Public Health. 1997 Aug;87(8):1328-34.

34. Trudeau F, Shephard RJ, Arsenault F, Laurencelle L. Changes in adiposity and body mass index from late childhood to adult life in the Trois-Rivières study. Am J Hum Biol. 2001 May-Jun;13(3):349-55.

35. Jamner MS, Spruijt-Metz D, Bassin S, Cooper DM. A controlled evaluation of a school-based intervention to promote physical activity among sedentary adolescent females: project FAB. J Adolesc Health. 2004 Apr;34(4):279-89.

36. Sallis JF, McKenzie TL, Alcaraz JE, Kolody B, Hovell MF, Nader PR. Project SPARK. Effects of physical education on adiposity in children. Ann N Y Acad Sci. 1993;699:127-36.

37. Trost SG, Kerr LM, Ward DS, Pate RR. Physical activity and determinants of physical activity in obese and non-obese children. Int J Obes Relat Metab Disord. 2001 Jun;25(6):822-9.

38. Ekelund U, Åman J, Yngve A, Renman C, Westerterp K, Sjöström M. Physical activity but not energy expenditure is reduced in obese adolescents: a case-control study. Am J Clin Nutr. 2002 Nov;76(5):935-41.

39. van Sluijs EM, Skidmore PM, Mwanza K, Jones AP, Callaghan AM, Ekelund U, et al. Physical activity and dietary behaviour in a populationbased sample of British 10-year old children: the SPEEDY study (Sport, Physical activity and Eating behaviour: environmental Determinants in Young people). BMC Public Health. 2008 Nov 14;8:388.

40. Ekelund U, Poortvliet E, Nilsson A, Yngve A, Holmberg A, Sjöström M. Physical activity in relation to aerobic fitness and body fat in 14- to 15-year-old boys and girls. Eur J Appl Physiol. 2001 Aug;85(3-4):195201.

41. Treuth MS, Hou N, Young DR, Maynard LM. Accelerometry-measured activity or sedentary time and overweight in rural boys and girls. Obes Res. 2005 Sep;13(9):1606-14.

42. Morrison KM, Bugge A, El-Naaman B, Eisenmann JC, Froberg K, Pfeiffer $\mathrm{KA}$, et al. Inter-relationships among physical activity, body fat, and motor performance in 6- to 8-year-old Danish children. Pediatr Exerc Sci. 2012 May;24(2):199-209.

43. Ekelund U, Sardinha LB, Anderssen SA, Harro M, Franks PW, Brage $\mathrm{S}$, et al. Associations between objectively assessed physical activity and indicators of body fatness in 9- to 10-y-old European children: a population-based study from 4 distinct regions in Europe (the European Youth Heart Study). Am J Clin Nutr. 2004 Sep;80(3):584-90.

44. Novak D, Petrović K, Tušak M, Kovač M. Sports class from the motoric, socio-demographic, psychological and micro sociological aspect. Ljubljana: University of Ljubljana; 1990. (In Slovene.)

45. Gubanc M. Sports classes in primary school - relevant condition for quality school? [dissertation]. Ljubljana: University of Ljubljana; 1999. (In Slovene.)

46. Baxter AP, Milner PC, Hawkins S, Leaf M, Simpson C, Wilson KV, et al. The impact of heart health promotion on coronary heart disease lifestyle risk factors in schoolchildren: lessons learnt from a community-based project. Public Health. 1997 Jul;111(4):231-7.

47. Lindberg LC, Ståhle A, Rydén L. Long-term influence of a health education programme on knowledge and health behaviour in children. Eur J Cardiovasc Prev Rehabil. 2006 Feb;13(1):91-7.

48. Walker Z, Townsend J, Oakley L, Donovan C, Smith H, Hurst Z, Bell $\mathrm{J}$, et al. Health promotion for adolescents in primary care: randomised controlled trial. BMJ. 2002 Sep 7;325(7363):524.

49. Harrison M, Burns CF, McGuinness M, Heslin J, Murphy NM. Influence of a health education intervention on physical activity and screen time in primary school children: 'Switch Off - Get Active'. J Sci Med Sport. 2006 Oct; $9(5): 388-94$

50. Verstraete SJ, Cardon GM, De Clercq DL, De Bourdeaudhuij IM. Increasing children's physical activity levels during recess periods in elementary schools: the effects of providing game equipment. Eur J Public Health. 2006 Aug; 16(4):415-9.

51. Jurg ME, Kremers SP, Candel MJ, Van der Wal MF, De Meij JS. A controlled trial of a school-based environmental intervention to improve physical activity in Dutch children: JUMP-in, kids in motion. Health Promot Int. 2006 Dec;21(4):320-30

52. Lopes L, Lopes V, Pereira B. Physical activity levels in normal weight and overweight Portuguese children: an intervention study during an elementary school recess. Int Electron J Health Educ. 2009;12:175-84.

53. Jurak G, Kovač M, Strel J. The opinions of class teachers about their competences for teaching physical education according to the new curriculum. In: Pišot R, Štemberger V, Zurc J, Obid A, editors. Abstracts and Proceedings of 3rd International Symposium ,.A child in motion“; 2004; Kranjska Gora, Slovenia [CD/ROM]. Koper: University of Primorska; 2004.

Received July 28, 2012 Accepted in revised form November 13, 2013 